\title{
What Can Gamma Delta T Cells Contribute to an HIV Cure?
}

\author{
Jennifer A. Juno ${ }^{1 *}$ and Stephen J. Kent ${ }^{1,2,3}$ \\ 1 Department of Microbiology and Immunology, The Peter Doherty Institute for Infection and Immunity, The University of \\ Melbourne, Melbourne, VIC, Australia, ${ }^{2}$ Department of Infectious Diseases, Melbourne Sexual Health Centre, Alfred Health, \\ Central Clinical School, Monash University, Clayton, VIC, Australia, ${ }^{3}$ ARC Centre of Excellence in Convergent Bio-Nano \\ Science and Technology, The University of Melbourne, Melbourne, VIC, Australia
}

Elimination of the latent HIV reservoir remains a major barrier to achieving an HIV cure. In this review, we discuss the cytolytic nature of human gamma delta T cells and highlight the emerging evidence that they can target and eliminate HIV-infected T cells. Based on observations from human clinical trials assessing gamma delta immunotherapy in oncology, we suggest key questions and research priorities for the study of these unique T cells in HIV cure research.

Keywords: gamma delta T cell, V $82, \mathrm{~V} \delta 1, \mathrm{HIV}$, immunotherapy

\section{OPEN ACCESS}

Edited by:

Alfredo Garzino-Demo, University of Maryland, United States

Reviewed by:

Natalia Soriano-Sarabia, George Washington University,

United States

Redmond Patrick Smyth, Helmholtz-Institut für RNA-basierte Infektionsforschung (HIRI), Germany

*Correspondence: Jennifer $A$. Juno jennifer.juno@unimelb.edu.au

Specialty section:

This article was submitted to Virus and Host,

a section of the journal

Frontiers in Cellular and Infection Microbiology

Received: 05 February 2020 Accepted: 23 April 2020 Published: 19 May 2020

Citation: Juno JA and Kent SJ (2020) What Can Gamma Delta T Cells Contribute to an HIV Cure?

Front. Cell. Infect. Microbiol. 10:233. doi: 10.3389/fcimb.2020.00233

\section{INTRODUCTION}

Efforts to eliminate the latent HIV reservoir have, to date, been unsuccessful, outside of aggressive chemotherapy and stem cell transplants from genetically resistant donors (Hutter et al., 2009; Gupta et al., 2020). Killing of infected cells with minimal viral replication, or killing of infected cells after latency reversal, is likely to be critical in the long-term containment or eradication of HIV. Novel approaches to clear infected cells now include the study and manipulation of highly cytotoxic lymphocyte subsets beyond traditional CD8+ CTL (Garrido et al., 2018a,b). It has become apparent from both in vitro studies and human clinical trials in oncology that gamma delta $\mathrm{T}(\gamma \delta \mathrm{T})$ cells exhibit remarkable cytotoxicity (Simoes et al., 2018) and the potential for safe clinical use in human immunotherapy (Silva-Santos et al., 2019). A number of excellent reviews have recently described the use of human $\gamma \delta \mathrm{T}$ cells in clinical trials for cancer treatment (Lo Presti et al., 2017; Godfrey et al., 2018; Pauza et al., 2018; Silva-Santos et al., 2019). Here, we will discuss how advances in gdT immunology have identified these cells as potential anti-HIV effectors, and what remains to be established regarding the efficacy of $\gamma \delta \mathrm{T}$ cells as components of an HIV cure intervention.

\section{HUMAN GAMMA DELTA T CELL SUBSETS}

Human $\gamma \delta$ T cells are typically classified on the basis of their TCR delta chain, of which there are 8 variants (Hayday, 2000). In peripheral blood, up to $90 \%$ of $\gamma \delta \mathrm{T}$ cells express the $\mathrm{V} \delta 2$ chain (Triebel et al., 1988). The majority of $\mathrm{V} \delta 2$ cells pair with $\mathrm{V} \gamma 9$ and form the well-studied population of phosphoantigen-reactive $\gamma \delta \mathrm{T}$ cells (Tanaka et al., 1995). In contrast, V $\delta 2$-negative $\gamma \delta \mathrm{T}$ s dominate at many mucosal sites, including the gut (Lundqvist et al., 1995). These V $\delta 2-\gamma \delta \mathrm{T}$ cells tend to express either the $\mathrm{V} \delta 1$ or $\mathrm{V} \delta 3$ chain, with a variety of $\mathrm{V} \gamma$ chain pairings (Groh et al., 1998). V $\delta 1$ cells typically, but not always (Hviid et al., 2000), form a minor population of the circulating $\gamma \delta \mathrm{T}$ cell compartment.

$\mathrm{V} \delta 2 \mathrm{~V} \gamma 9$ cells (herein referred to as $\mathrm{V} \delta 2$ cells) form a polyclonal $\mathrm{T}$ cell population that rapidly expands postnatally, most likely due to persistent antigen exposure or other inflammatory stimuli (Pauza and Cairo, 2015; van Der Heiden et al., 2020). The V $\delta 2 \mathrm{~V} \gamma 9$ TCR recognizes 
pyrophosphate antigens, which include isopentenyl pyrophosphate (IPP) and the potent microbial metabolite (E)-4-Hydroxy-3-methyl-but-2-enyl pyrophosphate (HMBPP) (Triebel et al., 1988). Like other unconventional T cells, however, $\mathrm{Vd} 2$ cells can also respond to TCR-independent stimuli, including cytokines such as IL-12 and IL-18, and various NK cell receptor ligands (Provine et al., 2018). Interestingly, phosphoantigen-reactive $\gamma \delta \mathrm{T}$ cells are found only in humans, non-human primates, and alpacas, with no $\gamma \delta \mathrm{T}$ cells in mice recognizing similar antigens (Fichtner et al., 2020). Owing in part to the ease with which they can be expanded in vitro, V $\delta 2$ cells have been well characterized in human health and disease, and many of their defining features have been recently reviewed (Tyler et al., 2015; Davey et al., 2018). Notably, V $\delta 2$ cells are commonly depleted during chronic HIV infection, with incomplete restoration among ART-treated cohorts (Hinz et al., 1994; Poccia et al., 1996; Wesch et al., 1998; Enders et al., 2003; Poles et al., 2003; Li et al., 2014, 2015; Cimini et al., 2015; Strbo et al., 2016; Bhatnagar et al., 2017). We have recently reviewed the impact of HIV infection and treatment on both circulating and tissue-resident $\gamma \delta$ T cells (Juno and Eriksson, 2019).

In contrast to $\mathrm{V} \delta 2$ cells, the antigen specificity of $\mathrm{V} \delta 1$ cells remains largely unknown. The $\mathrm{V} \delta 1$ cell population includes cells with specificity for R-phycoerythrin and EphA2 (Willcox and Willcox, 2019), CD1c- and CD1d-restricted lipid antigens (Uldrich et al., 2013; Roy et al., 2016; Willcox and Willcox, 2019), and the antigen presenting molecule MR1 (Le Nours et al., 2019). $\mathrm{V} \delta 1$ phenotype and frequency is markedly altered by infections such as malaria (Hviid et al., 2019) and human cytomegalovirus (HCMV) (Pitard et al., 2008; van Der Heiden et al., 2020). HCMV seropositivity is typically associated with substantial clonal expansion within the $\mathrm{V} \delta 1$ population, and differentiation toward a terminally differentiated (CD27-CD45RA+) phenotype (Davey et al., 2017; van Der Heiden et al., 2020). In contrast to $\mathrm{V} \delta 2$ cells, the $\mathrm{V} \delta 1$ cell population is significantly expanded during HIV infection and ART (De Paoli et al., 1991; De Maria et al., 1992; Rossol et al., 1998; Wesch et al., 1998; Poles et al., 2003; Poggi et al., 2004; Fausther-Bovendo et al., 2008; Li et al., 2014; Cimini et al., 2015; Olson et al., 2018; Chevalier et al., 2019), the implications of which are largely unknown (Juno and Eriksson, 2019).

\section{ANTI-HIV ACTIVITY OF GAMMA DELTA T CELLS}

Efforts to eliminate the HIV reservoir following latency reversal have traditionally focused on the utility of antigen-stimulated conventional CD8 + T cells to kill HIV-infected cells (Shan et al., 2012; Deng et al., 2015). Limitations to this approach include the requirement for autologous CD8 + T cells to be collected and prestimulated for each individual (Shan et al., 2012), as well as a high burden of CTL escape variants in the latent reservoir (Deng et al., 2015). More recently, other lymphocyte subsets have been considered for use in HIV cure approaches. Evidence suggests that cytokine-treated NK cells can eliminate HIV-infected T cells following ex vivo latency reactivation, although IL-15 treatment downregulates the expression of the key NK cell receptor NKp46, which may be undesirable in vivo (Garrido et al., 2018a). With a transcriptional phenotype that blends characteristics of both NK and CD8+ T cells (Gutierrez-Arcelus et al., 2019; Pizzolato et al., 2019), $\gamma \delta$ T cells are intriguing candidates to mediate anti$\mathrm{HIV}$ effector functions. Indeed, $\gamma \delta \mathrm{T}$-mediated inhibition of HIV replication has been recognized for more than 20 years (Poccia et al., 1999).

Like NK cells (Fehniger et al., 1998; Oliva et al., 1998), stimulated $\gamma \delta \mathrm{T}$ cells can produce sufficient $\beta$-chemokines to block HIV entry into either CCR5+ or CXCR4+ CD4+ T cells (Poccia et al., 1999; Omi et al., 2014). In the context of HIV cure approaches, however, it is the potent cytolytic function of $\gamma \delta$ T cells that makes them strong candidates for immunotherapy. Early reports suggested that direct cytotoxicity toward HIVinfected cells was largely restricted to V 82 cell clones (Wallace et al., 1996; Poccia et al., 1997), with little to no cytotoxicity observed among V $\delta 1$ cell lines (Wallace et al., 1996). More recently, V $\delta 1$ recognition and killing of $\mathrm{HIV}$-infected CD4+ T cells has been demonstrated (Fausther-Bovendo et al., 2008). Although it is challenging to determine the extent to which $\gamma \delta \mathrm{T}$ cells contribute to natural control of HIV infection in cross-sectional studies, elite/viral controllers do exhibit higher frequencies of $\mathrm{V} \delta 2$ cells than untreated or antiretroviral treated normal progressors (Riedel et al., 2009; Chevalier et al., 2019). A study in non-human primates identified a relationship between cervical V 22 frequency and simian immunodeficiency virus (SIV) viral load (Tuero et al., 2016), which supports the possibility of a protective role for these cells during infection.

Perhaps the strongest proof-of-concept evidence for V82mediated elimination of infected CD4 $+\mathrm{T}$ cells following latency reversal in vitro was reported by Garrido et al. (2018b). Despite low frequencies of $\mathrm{V} \delta 2$ cells in ART-treated donors ex vivo, pamidronate + IL-2 treatment successfully expanded the V $\delta 2$ population in a manner comparable to that of uninfected donors in vitro (i.e., a similar fold-increase). The expanded cells expressed CD56 and CD16, as well as relatively low levels of the inhibitory markers PD-1 and CTLA-4. Interestingly, both ex vivo isolated and in vitro expanded V $\delta 2$ cells were equally capable of inhibiting HIV replication in autologous superinfected $\mathrm{CD} 4+\mathrm{T}$ cells, with a level of inhibition comparable to that of CD8+ CTL. More importantly, however, expanded V $\delta 2$ cells degranulated in response to co-culture with HIV-infected, but not uninfected, CD4 $+\mathrm{T}$ cells. These results were further extended to a latency clearance assay, which demonstrated that expanded V $\delta 2$ cells cleared infected CD4+ T cells derived from ART-treated donors following in vitro reactivation with vorinostat. This study provides promising evidence for the ability of V $\delta 2$ cells to contribute to an HIV cure approach that relies on eliminating reactivated virally infected target cells. A number of important questions remain, however, particularly regarding the mechanisms of $\mathrm{V} \delta 2$ recognition of $\mathrm{HIV}$-infected cells as well as the optimal conditions for expansion V $\delta 2$ cells with the most potent cytotoxicity. The need to address these gaps in knowledge is evidenced in a recent study by James et al. (2020) which found that the presence of gamma delta $\mathrm{T}$ cells in a viral outgrowth assay impacted viral replication in 4 of 15 donors. CD16 expression 
on V $\delta 2$ cells correlated with a reduction in HIV recovery, but the key receptors involved in recognition of CD4 target cells and the reason for the heterogeneity in responses among the cohort remains unknown. Below, we explore the potential mechanisms that could be exploited in a gamma delta T-mediated HIV cure strategy (summarized in Figure 1).

\section{RECEPTORS MEDIATING DIRECT CYTOTOXICITY}

V $\delta 2$ cells express a number of receptors that might facilitate recognition of HIV-infected $\mathrm{T}$ cells. A critical receptor for the detection and killing of transformed and virally infected is NKG2D, which is commonly expressed on NK cells. NKG2D is widely expressed by $\mathrm{V} \delta 2$ cells both ex vivo and following in vitro expansion, and can mediate direct killing of target cells (RinconOrozco et al., 2005; Wrobel et al., 2007). The NKG2D ligands ULBP-1, -2 , and -3 are absent on uninfected CD4+ T cells, but are highly upregulated upon HIV infection and mediate NKcell killing of HIV-infected cells (Ward et al., 2007). NKG2D is therefore a strong candidate for $\mathrm{V} \delta 2$-mediated direct recognition and killing of reactivated HIV-infected cells. NK cells can also recognize infected $\mathrm{CD} 4+\mathrm{T}$ cells through 2B4-CD48 binding (Ward et al., 2007). Although 2B4 is highly expressed on V $\delta 2$ cells ex vivo, triggering of $2 \mathrm{~B} 4$ in isolation is insufficient to activate $\gamma \delta \mathrm{T}$ effector functions (Nakajima et al., 1999). Whether phosphoantigen-expanded V 82 cells can be activated through 2B4 signaling and/or recognition of CD48 on HIV-infected T cells is currently unknown. Similarly, there is a potential for V82-expressed DNAM-1 to recognize its ligand PVR on infected CD4+ T cells, although NK cell killing of infected cells through this mechanism seems to require signaling through both NKG2D and DNAM-1, rather than DNAM-1 alone (Cifaldi et al., 2019). In general, it will be important for future studies to consider the impact of activating receptor ligation both among ex vivoderived V $\delta 2$ cells, as well as in vitro expanded cells. For example, NKG2D ligation on resting V $\delta 2$ cells is reported to have either no or minimal functional impact (Rincon-Orozco et al., 2005; Nedellec et al., 2010), but in the context of TCR stimulation can provide robust co-stimulatory activity and effector function (Nedellec et al., 2010).

Expression of cytotoxicity receptors on $\mathrm{V} \delta 1$ cells differs substantially from those described on V $\delta 2$ cells. V $\delta 1$ cells commonly express CD94 paired with either the inhibitory receptor NKG2A (CD159a) or the activating receptor NKG2C (CD159c). Chronic HIV infection is associated with a significant increase in NKG2C expression on $\mathrm{V} \delta 1$ cells, which can substantially boost V $\delta 1$ cell cytotoxicity when triggered by binding to its ligand HLA-E (Fausther-Bovendo et al., 2008). Interestingly, V $\delta 1$ cells derived ex vivo from HIV-infected participants can lyse autologous HIV-infected CD4+ T cells in a manner which is partially dependent on V 81 NKG2C expression (Fausther-Bovendo et al., 2008), suggesting a currently unrealized potential for V $\delta 1$ cells in anti-HIV immunotherapy. The in vitro expansion of V $\delta 1$ cells is less commonly reported or standardized compared to V $\delta 2$ cells, largely due to the lack of an antigen that can easily stimulate the majority of $\mathrm{V} \delta 1$ cells ex vivo. Several groups, however, have reported protocols to expand these cells using a combination of $\gamma \delta$ TCR stimulus and cytokines. Almeida et al. reported on the production of "Delta One T (DOT)" cells using isolated $\gamma \delta \mathrm{T}$ cells, CD3 engagement and a cocktail of cytokines, which resulted in a 60,000-fold expansion of V $\delta 1$ cells in culture (Almeida et al., 2016). V $\delta 1$ expansion can also be induced through the culture of isolated $\gamma \delta \mathrm{T}$ cells with PHA and IL-7 (Wu et al., 2015). In both studies, expanded $\mathrm{V} \delta 1$ cells expressed a number of surface markers related to cytotoxic function, including NKp30, NKp44, NKp46, NKG2D, 2B4, DNAM-1, and CD94. Other approaches to expand V $\delta 1$ cells include the use of artificial APCs (aAPCs) presenting CMVderived peptides (Polito et al., 2019). V $\delta 1$ cells expanded by this approach recognize an array of tumor cells and virally infected cell lines, but the mechanism underlying this recognition was not assessed. Although the translational potential of DOT cells and other expanded V $\delta 1$ cells are currently focussed on cancer immunotherapy, the expression of traditionally $\mathrm{NK}$ cell-associated markers such as NKp44, NKG2D, and 2B4 on expanded $V \delta 1$ cells may also mediate recognition of HIV-infected CD4+ T cells (Ward et al., 2007).

\section{ANTIBODY-DEPENDENT CYTOTOXICITY}

In addition to direct recognition and killing of HIV-infected target cells, HIV-specific antibodies can mediate antibodydependent cellular cytotoxicity (ADCC) via Fc receptorexpressing cells such as NK cells. Naturally occurring anti-HIV ADCC antibodies decline following ART (Madhavi et al., 2015, 2017) and are not boosted following panobinostat administration (as a latency-reversing agent, LRA) and subsequent analytical treatment interruption (ATI) (Lee et al., 2017). This suggests such antibodies may be insufficient to mediate the level of ADCC needed to clear the latent reservoir. The infusion of more potent broadly neutralizing antibodies (BnAbs), however, may be sufficient to allow FcR-expressing cells to recognize Env expression on reactivated infected cells (Bruel et al., 2016). HIVspecific ADCC has been widely studied in the context of NK cells, but less so in relation to unconventional T cells. Both $\mathrm{V} \delta 1$ and V $\delta 2$ cells can express FcgRIIIA (CD16) (Angelini et al., 2004; Couzi et al., 2012; He et al., 2013), making them potential mediators of ADCC in the context of latency reactivation and BnAb therapy.

Despite depletion of V $\delta 2$ cells during chronic HIV infection, ART-treated individuals exhibit similar frequencies of CD16+ V $\delta 2$ cells compared to uninfected controls (although there is intra-donor variability in steady-state CD16 expression) (He et al., 2013). As such, ex vivo CD16-mediated degranulation responses are comparable between these groups (He et al., 2013), suggesting that primary V $\delta 2$ cells from ART-treated individuals are capable of performing ADCC. Poonia and Pauza (2012) demonstrated that zoledronate can expand V 82 cells in vitro from both HIV-uninfected and HIV-infected donors, with expression of CD16 detectible on a subset of the expanded cells. Although expanded V $\delta 2$ cells from HIV-infected donors 


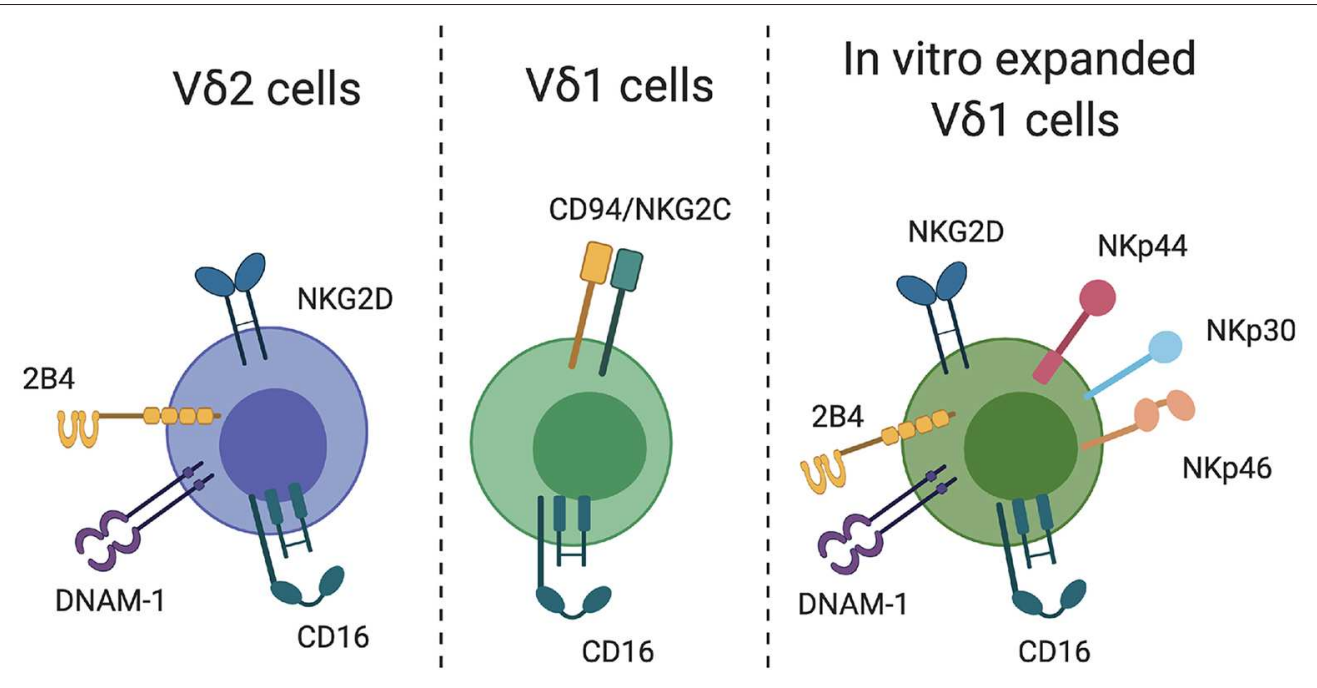

FIGURE $1 \mid \gamma \delta$ T cell recognition of target cells. Relevant receptors that may facilitate $\gamma \delta \mathrm{T}$ cell recognition of HIV-infected CD4 T cells are indicated for V82, V81, and in vitro-expanded $\mathrm{V} \delta 1$ cells.

exhibited lower ADCC than those from uninfected donors, they remained capable of degranulation and cytokine expression following CD16 cross-linking.

The expression of CD16 on V $\delta 1$ cells has been studied in the context of HCMV infection (Couzi et al., 2012; Bachelet et al., 2014) and cancer immunotherapy (Fisher et al., 2014), but despite the high prevalence of HCMV seropositivity among HIV-infected populations (Gianella and Letendre, 2016), there has been little study of V $\delta 1$ ADCC in the context of HIV infection. The expanded population of $\mathrm{V} \delta 1$ cells in HIVinfected individuals exhibits high expression of perforin (Boullier et al., 1997), but whether this translates into antibody-mediated cytotoxicity is unknown. Similar gaps in knowledge exist for in vitro-expanded V $\delta 1$ cells. There is no data available to describe CD16 expression on DOT cells (Almeida et al., 2016), while PHA/IL-7-expanded V $\delta 1$ cells express moderate levels of CD16 and high levels of GzmB and Perforin, though they have not been assessed for ADCC activity (Wu et al., 2015).

\section{APPROACHES FOR GAMMA DELTA IMMUNOTHERAPY}

As described above, there are many in vitro protocols that result in $\mathrm{Vd} 2$ or $\mathrm{Vd} 1 \mathrm{~T}$ cell expansion from bulk PBMC. To translate these ideas to the clinic, there are two major approaches that can be considered: in vivo gamma delta $\mathrm{T}$ cell expansion, or adoptive transfer of in vitro-expanded cells. Currently, in vivo expansion has only been demonstrated for human $\mathrm{Vd} 2 \mathrm{~T}$ cells. This method involves the administration of zoledronate and recombinant IL-2, and has successfully expanded Vd2 T cells in HIV-infected participants in a small clinical trial (Poccia et al., 2009). An advantage of this approach is that it is relatively simple and involves an existing, clinically approved drug (under the brand name Zometa). It would not, however, likely be suitable for individuals with substantial Vd2 T cell depletion/exhaustion or $\mathrm{Vd} 2 \mathrm{~T}$ cell phenotypes that lack the receptors determined to be key in recognizing HIV-infected target cells. In such instances, it may be more attractive to consider the use of "off-the-shelf," in vitro-expanded gamma delta T cells derived from HIV uninfected donors. Such cells could be expanded by any of the protocols described above, and could include both $\mathrm{Vd} 2$ and $\mathrm{Vd} 1 \mathrm{~T}$ cell subsets. This approach has been tested in clinical trials for cancer patients (Lo Presti et al., 2017) and also used in studies of non-human primate Vd2 T cells (Qaqish et al., 2017).

\section{ACCESSING THE LATENT HIV RESERVOIR}

While in vitro studies can provide an important assessment of cytotoxic capacity and recognition of infected T cells, they largely ignore one of the major barriers to achieving an HIV cure: the anatomical localization of the latent reservoir. Recent evidence suggests that the B cell follicle is a key site of HIV replication, even during ART (Bronnimann et al., 2018). Germinal center (GC) T follicular helper (Tfh) cells are highly permissive to HIV infection (Kohler et al., 2016; Aid et al., 2018), while follicular dendritic cells (FDCs) can capture HIV virions and maintain an infectious virus reservoir even during ART (Smith et al., 2001; Bronnimann et al., 2018). A major barrier to the clearance of virus from the B cell follicle is the fact that the follicle is partially protected from CTL activity. Of the few CTLs found in the follicle, many may be exhausted or exhibit a regulatory phenotype (Bronnimann et al., 2018). Similarly, there are few NK cells found in the human lymph node, and a high proportion of LN NK cells in HIV-infected individuals exhibit an anergic CD56CD16+ phenotype (Luteijn et al., 2011). Given these limitations, expanded $\gamma \delta \mathrm{T}$ cells may be strong candidates for B cell follicle targeting and elimination of infected cells. V $\delta 2$ cells can acquire a Tfh-like phenotype, complete with expression of the GC-homing marker CXCR5 (Caccamo et al., 2006; Bansal et al., 2012), and 
such cells have been described both in vitro and in vivo in human lungs (Caccamo et al., 2006). Furthermore, $\gamma \delta \mathrm{T}$ cells have been visualized within GCs in the gastrointestinal mucosa, lymph nodes, tonsil and spleen, likely due to the induction of a LN migration program that occurs following V $\delta 2$ TCR triggering (Brandes et al., 2003). Functional studies of V $\delta 2 \mathrm{Tfh}$ cells have largely focused on their capacity to provide B cell help, leaving open the question of their cytotoxic potential and expression of cytotoxicity receptors. Nonetheless, the fact that $\gamma \delta \mathrm{T}$ cells appear to access the B cell follicle merits further study of their potential to eliminate HIV-infected cells in this unique environment (Bronnimann et al., 2018).

Beyond the B cell follicle, many other tissues serve as HIV reservoir sites, including the spleen, bone marrow, liver, gut, nervous system, lung, and male and female reproductive tracts (Wong and Yukl, 2016; Cantero-Perez et al., 2019). Infection of tissue-resident $\mathrm{T}$ cells may be particularly important, given their longevity and capacity for self-renewal (Cantero-Perez et al., 2019). Both expanded V $\delta 1$ and V $\delta 2$ cells appear to be excellent candidates for tissue trafficking in vivo. When administered to mice, human-derived DOT cells seeded, and then further expanded in, various tissues including the spleen, lung, bone marrow, and liver (Almeida et al., 2016). The tissue-resident cells retained function, as assessed by IFNg and TNF production, and exhibited evidence of ongoing proliferation. Similarly, the adoptive transfer of expanded V $\delta 2$ cells has been studied in nonhuman primates. Infusion of zoledronate-expanded V $\delta 2$ cells resulted in trafficking to and persistence in the airway for at least 7 days (Qaqish et al., 2017).

\section{POTENTIAL ADVANTAGES AND DISADVANTAGES OF $\gamma \delta$ T CELL IMMUNOTHERAPY}

As with any immune-based intervention, there are both key advantages offered by $\gamma \delta \mathrm{T}$ cells over other $\mathrm{T}$ cell therapies and issues that will need to be addressed prior to clinical testing.

Advantages of $\gamma \delta \mathrm{T}$ cell-based immunotherapy include:

1) Lack of MHC restriction: GMP-compliant protocols have been developed to generate large banks of expanded $\gamma \delta \mathrm{T}$ cells, allowing for an "off-the-shelf" allogeneic product that is not reliant on MHC matching (Deniger et al., 2014; Almeida et al., 2016; Polito et al., 2019). The lack of MHC-restriction of $\gamma \delta \mathrm{T}$ cells is a major advantage that should avoid issues of graft-vs.-host disease in $\gamma \delta \mathrm{T}$-based immunotherapy. Indeed, adoptive transfer of haploidentical expanded $\gamma \delta \mathrm{T}$ cells from the family members of cancer patients proved to be safe and highly effective toward achieving complete remission (Wilhelm et al., 2014).

2) Safety: Clinical trials of human $\gamma \delta T$ cell therapy, either using in vivo $\mathrm{V} \delta 2$ expansion or adoptive transfer of expanded V $\delta 2$ cells, have proven to be safe and well-tolerated (Lo Presti et al., 2017). A major disadvantage to current $\alpha \beta$ T cell-based chimeric antigen receptor (CAR)-T cell therapies is the potential for serious and/or fatal side effects, including cytokine release syndrome (van Den Berg et al., 2015), off-target effects due to antigen cross-reactivity (Linette et al., 2013), or transgenic TCR mispairing with endogenous TCR (Zhang et al., 2004). Several studies suggest that $\gamma \delta \mathrm{T}$-based immunotherapy is less likely to result in cytokine release syndrome (CRS) or off-target effects than $\alpha \beta$ T cells (Harrer et al., 2017; Pauza et al., 2018; Rotolo et al., 2019). Indeed, expanded $\gamma \delta \mathrm{T}$ cells can mediate potent cytotoxicity but simultaneously produce lower levels of cytokines than $\alpha \beta$ T cells (Harrer et al., 2017).

3) HIV-associated expansion and differentiation of Vd1 cells: As discussed in the introduction, $V \delta 1$ cell frequency and absolute counts increase in the circulation during HIV infection. This increase persists during suppressive ART, resulting in a pool of terminally differentiated V $\delta 1$ cells (Olson et al., 2018) that express NCRs such as NKG2C (Fausther-Bovendo et al., 2008). To date, we are not aware of any studies that have assessed the expansion and subsequent anti-HIV cytotoxicity of V $\delta 1$ cells specifically derived from HIV-infected individuals. If expansion of $\mathrm{V} \delta 1$ cells from healthy donors does not induce the expression of NKG2C or other NCRs that are upregulated during HIV infection, then it may be advantageous to isolate and expand V $\delta 1$ cells expressing these markers from people living with HIV. Care must be taken, however, to characterize the pro-inflammatory nature of these cells, as discussed below.

Potential challenges to $\gamma \delta \mathrm{T}$ cell-based immunotherapy include:

1) In vivo potency: One of the major challenges facing the implementation of $\gamma \delta \mathrm{T}$ cell therapy in cancer is a discrepancy between in vitro and in vivo $\gamma \delta \mathrm{T}$ cell potency (Pauza et al., 2018). In vitro, $\gamma \delta \mathrm{T}$ cell cytotoxicity can be achieved with effector:target ratios of $<1$, but results of human clinical trials show considerably more heterogeneity in objective responses to $\gamma \delta \mathrm{T}$ immunotherapy (Pauza et al., 2018). Pre-clinical animal studies are hindered by the fact that $\mathrm{V} \delta 2 \mathrm{Vg} 9$ phosphoantigenreactive $\mathrm{T}$ cells are found only in humans and non-human primates (NHP). Studies in mouse models are therefore less informative and have more caveats than studies of other lymphocyte subsets. In the context of HIV infection, it will be critical to move studies into NHPs and SIV infection prior to human clinical trials.

2) $\gamma \delta T$ cell infection by HIV: Typically, both $\mathrm{V} \delta 1$ and $V \delta 2$ cells lack expression of the HIV co-receptor CD4, seemingly rendering them refractory to direct infection. Concerningly, however, Soriano-Sarabia et al. (2015) reported that replicationcompetent HIV could be recovered from purified V $\delta 2$ cells in 14 of 18 long-term ART recipients. Thus, the use of expanded autologous V $\delta 2$ cells from HIV-infected patients may risk the reactivation and replication of a latent reservoir. This could be mitigated by the use of haploidentical or third-party V $\delta 2$ cells from HIV-uninfected donors. Even in that scenario, though, consideration must be given to whether large numbers of adoptively transferred V $\delta 2$ cells could be infected by HIV, since $\gamma \delta$ immunotherapy would be reliant on the use of LRAs to reactivate the latent reservoir. Several reports now suggest that V 22 cells can transiently express CD4 during activation (Imlach et al., 2003; Soriano-Sarabia et al., 2015; Strbo et al., 2016) and can be productively infected with HIV (Wallace et al., 1997), which likely mediates the establishment of the latent reservoir detected by Soriano-Sarabia. For that reason, in vitro V $\delta 2$ expansion and 
adoptive transfer may be preferable compared to in vivo $\mathrm{V} \delta 2$ expansion using aminobisphosphonate drugs.

3) Depletion of $V \delta 2$ cells: In contrast to $V \delta 1$ cells, $V \delta 2$ cells are depleted during HIV infection and do not fully recover following ART (as discussed previously). Most data suggest that V $\delta 2$ cells expand in vitro to a similar extent regardless of the HIV status of the donor, but individuals who exhibit low V $\delta 2$ frequencies ex vivo will produce fewer absolute numbers of $\mathrm{V} \delta 2$ cells after expansion (Garrido et al., 2018b). Furthermore, the observation that the ADCC activity of V $\delta 2$ cells derived from ART-treated donors was reduced compared to uninfected donors (Poonia and Pauza, 2012) suggests that further attention needs to be paid to functional defects of V $\delta 2$ cells in HIV-infected donors.

4) Contribution to immune activation: While the causes of V $\delta 1$ expansion during HIV infection are not conclusively known, it is likely that microbial translocation and loss of epithelial barrier integrity in the gut mucosa drive activation and differentiation of this subset (Harris et al., 2010; Olson et al., 2018). Some studies have shown that V $\delta 1$ cells exhibit proinflammatory cytokine production that correlates with CD8+ $\mathrm{T}$ cell activation (Olson et al., 2018) or killing of bystander CD4+ T cells (Sindhu et al., 2003) during HIV infection. Thorough assessment of the characteristics of expanded V $\delta 1$ cells derived from HIV-infected donors will be required to determine the potential pathogenic impact of these cells if adoptively transferred.

\section{CONCLUDING THOUGHTS AND FUTURE DIRECTIONS}

Intense interest in $\gamma \delta \mathrm{T}$ cell-based immunotherapy for cancer is continually driving innovative and novel approaches to harness $\gamma \delta \mathrm{T}$ cell cytotoxicity, which should be considered in the context of HIV cure strategies. For example, despite substantial differences in antigen specificity, NK cell receptor expression, and tissue tropism between $\mathrm{V} \delta 1$ and $\mathrm{V} \delta 2$ cells, it may be more effective to non-specifically expand a diverse population of $\gamma \delta \mathrm{T}$ cells than to focus on the development of pure $V \delta 1$ or $V \delta 2$ populations. Using aAPCs engineered to express a number of co-stimulatory molecules, Deniger et al. (2014) demonstrated the expansion of a mixed population of $\mathrm{V} \delta 1, \mathrm{~V} \delta 2$, and $\mathrm{V} \delta 1-\mathrm{V} \delta 2$ - cells that recognized tumor cells via NKG2D, DNAM-1, and the $\gamma \delta$ TCR. In an in vivo murine model, this mixed population was more effective at eliminating ovarian cancer xenografts than any of the individual $\gamma \delta \mathrm{T}$ subsets alone. Similar results were obtained with mixed $\gamma \delta \mathrm{T}$ cells in a model of neuroblastoma, where $\mathrm{V} \delta 2$ cells mediated CD16-dependent ADCC and Vd1 cells exhibited direct cytotoxicity (Fisher et al., 2014). Given the utility of both

\section{REFERENCES}

Aid, M., Dupuy, F. P., Moysi, E., Moir, S., Haddad, E. K., Estes, J. D., et al. (2018). Follicular CD4 T helper cells as a major HIV reservoir compartment: a molecular perspective. Front. Immunol. 9:895. doi: 10.3389/fimmu.2018.00895

Ali, Z., Shao, L., Halliday, L., Reichenberg, A., Hintz, M., Jomaa, H., et al. (2007). Prolonged (E)-4-hydroxy-3-methyl-but-2-enyl
ADCC-based and direct recognition of HIV-infected T cells in cure strategies, mixed $\gamma \delta \mathrm{T}$ expansion may be a potent method by which to generate effector $\gamma \delta \mathrm{T}$ cells. More complex approaches could also engineer such cells to express a CAR, providing an additional mechanism by which to recognize infected cells (Rotolo et al., 2019).

Regardless of the nature of the $\gamma \delta \mathrm{T}$ cells chosen for study, the path forward for $\gamma \delta \mathrm{T}$ immunotherapy in HIV cure is clear: First, incisive mechanistic studies are needed to establish the most efficient mechanisms of $\gamma \delta \mathrm{T}$ recognition of reactivated HIVinfected target cells. Despite the intriguing results of Garrido et al. (2018b), the latency-clearing capacity of V $\delta 2$ cells needs to be replicated and the mechanism of recognition defined. With this information, it may be possible to identify $\gamma \delta \mathrm{T}$ cell subsets whose selective expansion would generate better effector cell populations compared to bulk expansion protocols. Second, in vivo animal studies using non-human primates will be critical to addressing questions of tissue targeting and assessment of in vivo potency. Reagents exist to characterize both V $\delta 1$ and V $\delta 2$ cells in NHPs, and studies confirm that these cells recapitulate many aspects of human immunology including expression of CD16 (Hodara et al., 2014), NKG2D, NKG2A, GzmB, and CD107a (Tuero et al., 2016), as well as the ability to kill SIV-infected cells (Malkovsky et al., 1992; Wallace et al., 1994). SIV-infected macaques also recapitulate important aspects of HIV-infected human cohorts, including inversion of the $\mathrm{V} \delta 1: \mathrm{V} \delta 2$ ratio and microbial translocation-induced expansion of $\mathrm{V} \delta 1$ cells (Harris et al., 2010). Critically, translational studies of immunity to Mycobacterium tuberculosis have demonstrated the feasibility of both expanding macaque V $\delta 2$ cells in vivo (Ali et al., 2007) or adoptively transferring in vitro expanded cells (Qaqish et al., 2017). With these goals in mind, the application of $\gamma \delta \mathrm{T}$-based immunotherapy to HIV cure strategies represents an exciting and informative research avenue.

\section{AUTHOR CONTRIBUTIONS}

JJ and SK wrote and edited the manuscript.

\section{FUNDING}

JJ and SK were supported by NHMRC Fellowships (APP1123673 and APP1136322).

\section{ACKNOWLEDGMENTS}

The authors would like to acknowledge Wen Shi Lee and Kathleen Wragg for providing feedback on the manuscript. pyrophosphate-driven antimicrobial and cytotoxic responses of pulmonary and systemic $\mathrm{V} \gamma 2 \mathrm{~V} \delta 2 \mathrm{~T}$ cells in macaques. J. Immunol. 179, 8287-8296. doi: 10.4049/jimmunol.179.12.8287

Almeida, A. R., Correia, D. V., Fernandes-Platzgummer, A., Da Silva, C. L., Da Silva, M. G., Anjos, D. R., et al. (2016). $\Delta$ one T cells for immunotherapy of chronic lymphocytic leukemia: clinicalgrade expansion/differentiation and preclinical proof of concept. 
Clin. Cancer Res. 22, 5795-5804. doi: 10.1158/1078-0432.CCR-1 6-0597

Angelini, D. F., Borsellino, G., Poupot, M., Diamantini, A., Poupot, R., Bernardi, G., et al. (2004). Fc $\gamma$ RIII discriminates between 2 subsets of V $\gamma 9 \mathrm{~V} \delta 2$ effector cells with different responses and activation pathways. Blood 104, 1801-1807. doi: 10.1182/blood-2004-01-0331

Bachelet, T., Couzi, L., Pitard, V., Sicard, X., Rigothier, C., Lepreux, S., et al. (2014). Cytomegalovirus-responsive $\gamma \delta$ T cells: novel effector cells in antibodymediated kidney allograft microcirculation lesions. J. Am. Soc. Nephrol. 25, 2471-2482. doi: 10.1681/ASN.2013101052

Bansal, R. R., Mackay, C. R., Moser, B., and Eberl, M. (2012). IL-21 enhances the potential of human $\gamma \delta \mathrm{T}$ cells to provide B-cell help. Eur. J. Immunol. 42, 110-119. doi: 10.1002/eji.201142017

Bhatnagar, N., Girard, P. M., Lopez-Gonzalez, M., Didier, C., Collias, L., Jung, C., et al. (2017). Potential role of $\mathrm{V} \delta 2(+) \gamma \delta \mathrm{T}$ cells in regulation of immune activation in primary HIV infection. Front. Immunol. 8:1189. doi: 10.3389/fimmu.2017.01189

Boullier, S., Dadaglio, G., Lafeuillade, A., Debord, T., and Gougeon, M. L. (1997). V $\delta 1 \mathrm{~T}$ cells expanded in the blood throughout HIV infection display a cytotoxic activity and are primed for TNF-alpha and IFN- $\gamma$ production but are not selected in lymph nodes. J. Immunol. 159, 3629-3637.

Brandes, M., Willimann, K., Lang, A. B., Nam, K. H., Jin, C., Brenner, M. B., et al. (2003). Flexible migration program regulates $\gamma \delta$ T-cell involvement in humoral immunity. Blood 102, 3693-3701. doi: 10.1182/blood-2003-04-1016

Bronnimann, M. P., Skinner, P. J., and Connick, E. (2018). The B-cell follicle in HIV infection: barrier to a cure. Front. Immunol. 9:20. doi: 10.3389/fimmu.2018.00020

Bruel, T., Guivel-Benhassine, F., Amraoui, S., Malbec, M., Richard, L., Bourdic, K., et al. (2016). Elimination of HIV-1-infected cells by broadly neutralizing antibodies. Nat. Commun. 7:10844. doi: 10.1038/ncomms10844

Caccamo, N., Battistini, L., Bonneville, M., Poccia, F., Fournie, J. J., Meraviglia, S., et al. (2006). CXCR5 identifies a subset of $\mathrm{V} \gamma 9 \mathrm{~V} \delta 2 \mathrm{~T}$ cells which secrete IL-4 and IL-10 and help B cells for antibody production. J. Immunol. 177, 5290-5295. doi: 10.4049/jimmunol.177.8.5290

Cantero-Perez, J., Grau-Exposito, J., Serra-Peinado, C., Rosero, D. A., LuqueBallesteros, L., Astorga-Gamaza, A., et al. (2019). Resident memory T cells are a cellular reservoir for HIV in the cervical mucosa. Nat. Commun. 10:4739. doi: 10.1038/s41467-019-12732-2

Chevalier, M. F., Bhatnagar, N., Didier, C., Lopez-Gonzalez, M., Pavie, J., Bollens, D., et al. (2019). $\gamma \delta$ T-cell subsets in HIV controllers: potential role of $\mathrm{T} \gamma \delta$ 17 cells in the regulation of chronic immune activation. Aids 33, 1283-1292. doi: 10.1097/QAD.0000000000002196

Cifaldi, L., Doria, M., Cotugno, N., Zicari, S., Cancrini, C., Palma, P., et al. (2019). DNAM-1 Activating receptor and its ligands: how do viruses affect the NK cellmediated immune surveillance during the various phases of infection? Int. J. Mol. Sci. 20:3715. doi: 10.3390/ijms20153715

Cimini, E., Agrati, C., D’offizi, G., Vlassi, C., Casetti, R., Sacchi, A., et al. (2015). Primary and chronic HIV infection differently modulates mucosal V $\delta 1$ and V $\delta 2$ T-cells differentiation profile and effector functions. PLOS ONE 10:e129771. doi: 10.1371/journal.pone.0129771

Couzi, L., Pitard, V., Sicard, X., Garrigue, I., Hawchar, O., Merville, P., et al. (2012). Antibody-dependent anti-cytomegalovirus activity of human $\gamma \delta \mathrm{T}$ cells expressing CD16 (Fc $\gamma$ RIIIa). Blood 119, 1418-1427. doi: 10.1182/blood-2011-06-363655

Davey, M. S., Willcox, C. R., Hunter, S., Oo, Y. H., and Willcox, B. E. (2018). $\mathrm{V} \delta 2(+) \mathrm{T}$ cells-two subsets for the price of one. Front. Immunol. 9:2106. doi: 10.3389/fimmu.2018.02106

Davey, M. S., Willcox, C. R., Joyce, S. P., Ladell, K., Kasatskaya, S. A., Mclaren, J. E., et al. (2017). Clonal selection in the human V $\delta 1 \mathrm{~T}$ cell repertoire indicates $\gamma \delta$ TCR-dependent adaptive immune surveillance. Nat. Commun. 8:14760. doi: $10.1038 /$ ncomms 14760

De Maria, A., Ferrazin, A., Ferrini, S., Ciccone, E., Terragna, A., and Moretta, L. (1992). Selective increase of a subset of T cell receptor $\gamma \delta$ T lymphocytes in the peripheral blood of patients with human immunodeficiency virus type 1 infection. J. Infect. Dis. 165, 917-919. doi: 10.1093/infdis/165.5.917

De Paoli, P., Gennari, D., Martelli, P., Basaglia, G., Crovatto, M., Battistin, S., et al. (1991). A subset of $\gamma \delta$ lymphocytes is increased during HIV-1 infection. Clin. Exp. Immunol. 83, 187-191. doi: 10.1111/j.1365-2249.1991.tb05612.x
Deng, K., Pertea, M., Rongvaux, A., Wang, L., Durand, C. M., Ghiaur, G., et al. (2015). Broad CTL response is required to clear latent HIV-1 due to dominance of escape mutations. Nature 517, 381-385. doi: 10.1038/nature14053

Deniger, D. C., Maiti, S. N., Mi, T., Switzer, K. C., Ramachandran, V., Hurton, L. V., et al. (2014). Activating and propagating polyclonal $\gamma \delta \mathrm{T}$ cells with broad specificity for malignancies. Clin. Cancer Res. 20, 5708-5719. doi: 10.1158/1078-0432.CCR-13-3451

Enders, P. J., Yin, C., Martini, F., Evans, P. S., Propp, N., Poccia, F., et al. (2003). $\mathrm{HIV}$-mediated $\gamma \delta \mathrm{T}$ cell depletion is specific for $\mathrm{V} \gamma 2+$ cells expressing the $\mathrm{J} \gamma 1.2$ segment. AIDS Res. Hum. Retrovir. 19, 21-29. doi: 10.1089/08892220360473934

Fausther-Bovendo, H., Wauquier, N., Cherfils-Vicini, J., Cremer, I., Debre, P., and Vieillard, V. (2008). NKG2C is a major triggering receptor involved in the $\mathrm{V}[\delta] 1 \mathrm{~T}$ cell-mediated cytotoxicity against HIV-infected CD4 T cells. Aids 22, 217-226. doi: 10.1097/QAD.0b013e3282f46e7c

Fehniger, T. A., Herbein, G., Yu, H., Para, M. I., Bernstein, Z. P., O'brien, W. A., et al. (1998). Natural killer cells from HIV-1+ patients produce C-C chemokines and inhibit HIV-1 infection. J. Immunol. 161, 6433-6438.

Fichtner, A. S., Karunakaran, M. M., Gu, S., Boughter, C. T., Borowska, M. T., Starick, L., et al. (2020). Alpaca (Vicugna pacos), the first nonprimate species with a phosphoantigen-reactive V $\gamma 9 \mathrm{~V} \delta 2 \mathrm{~T}$ cell subset. Proc. Natl. Acad. Sci. U.S.A. 117, 6697-6707. doi: 10.1073/pnas.1909474117

Fisher, J. P., Yan, M., Heuijerjans, J., Carter, L., Abolhassani, A., Frosch, J., et al. (2014). Neuroblastoma killing properties of $\mathrm{V} \delta 2$ and $\mathrm{V} \delta 2$-negative $\gamma \delta \mathrm{T}$ cells following expansion by artificial antigen-presenting cells. Clin. Cancer Res. 20, 5720-5732. doi: 10.1158/1078-0432.CCR-13-3464

Garrido, C., Abad-Fernandez, M., Tuyishime, M., Pollara, J. J., Ferrari, G., SorianoSarabia, N., et al. (2018a). Interleukin-15-stimulated natural killer cells clear HIV-1-infected cells following latency reversal ex vivo. J. Virol. 92:JVI.00235-18. doi: 10.1128/JVI.00235-18

Garrido, C., Clohosey, M. L., Whitworth, C. P., Hudgens, M., Margolis, D. M., and Soriano-Sarabia, N. (2018b). $\Gamma \delta$ T cells: an immunotherapeutic approach for HIV cure strategies. JCI Insight 3: e120121. doi: 10.1172/jci.insight.120121

Gianella, S., and Letendre, S. (2016). Cytomegalovirus and HIV: a Dangerous Pas de Deux. J. Infect. Dis. 214(Suppl. 2), S67-74. doi: 10.1093/infdis/jiw217

Godfrey, D. I., Le Nours, J., Andrews, D. M., Uldrich, A. P., and Rossjohn, J. (2018). Unconventional T cell targets for cancer immunotherapy. Immunity 48, 453-473. doi: 10.1016/j.immuni.2018.03.009

Groh, V., Steinle, A., Bauer, S., and Spies, T. (1998). Recognition of stress-induced MHC molecules by intestinal epithelial $\gamma \delta \mathrm{T}$ cells. Science 279, 1737-1740. doi: 10.1126/science.279.5357.1737

Gupta, R. K., Peppa, D., Hill, A. L., Galvez, C., Salgado, M., Pace, M., et al. (2020). Evidence for HIV-1 cure after CCR5 $\Delta 32 / \Delta 32$ allogeneic haemopoietic stemcell transplantation 30 months post analytical treatment interruption: a case report. Lancet HIV. 7, e340-347. doi: 10.1016/S2352-3018(20)30069-2

Gutierrez-Arcelus, M., Teslovich, N., Mola, A. R., Polidoro, R. B., Nathan, A., Kim, H., et al. (2019). Lymphocyte innateness defined by transcriptional states reflects a balance between proliferation and effector functions. Nat. Commun. 10:687. doi: 10.1038/s41467-019-08604-4

Harrer, D. C., Simon, B., Fujii, S. I., Shimizu, K., Uslu, U., Schuler, G., et al. (2017). RNA-transfection of $\gamma / \delta$ T cells with a chimeric antigen receptor or an alpha/beta T-cell receptor: a safer alternative to genetically engineered alpha/beta T cells for the immunotherapy of melanoma. BMC Cancer 17:551. doi: 10.1186/s12885-017-3539-3

Harris, L. D., Klatt, N. R., Vinton, C., Briant, J. A., Tabb, B., Ladell, K., et al. (2010). Mechanisms underlying $\gamma \delta$ T-cell subset perturbations in SIV-infected Asian rhesus macaques. Blood 116, 4148-4157. doi: 10.1182/blood-2010-05-283549

Hayday, A. C. (2000). $[\gamma][\delta]$ cells: a right time and a right place for a conserved third way of protection. Annu. Rev. Immunol. 18, 975-1026. doi: 10.1146/annurev.immunol.18.1.975

He, X., Liang, H., Hong, K., Li, H., Peng, H., Zhao, Y., et al. (2013). The potential role of CD16+ V $\gamma 2 \mathrm{~V} \delta 2 \mathrm{~T}$ cell-mediated antibody-dependent cell-mediated cytotoxicity in control of HIV type 1 disease. AIDS Res. Hum. Retrovir. 29, 1562-1570. doi: 10.1089/aid.2013.0111

Hinz, T., Wesch, D., Friese, K., Reckziegel, A., Arden, B., and Kabelitz, D. (1994). T cell receptor $\gamma \delta$ repertoire in HIV-1-infected individuals. Eur. J. Immunol. 24, 3044-3049. doi: 10.1002/eji.1830241219

Hodara, V. L., Parodi, L. M., Chavez, D., Smith, L. M., Lanford, R., and Giavedoni, L. D. (2014). Characterization of $\gamma \delta$ T cells in naive and HIV-infected 
chimpanzees and their responses to T-cell activators in vitro. J. Med. Primatol. 43, 258-271. doi: 10.1111/jmp. 12115

Hutter, G., Nowak, D., Mossner, M., Ganepola, S., Mussig, A., Allers, K., et al. (2009). Long-term control of HIV by CCR $\Delta 32 / \Delta 32$ stem-cell transplantation. N Engl. J. Med. 360, 692-698. doi: 10.1056/NEJMoa0802905

Hviid, L., Akanmori, B. D., Loizon, S., Kurtzhals, J. A., Ricke, C. H., Lim, A., et al. (2000). High frequency of circulating $\gamma \delta \mathrm{T}$ cells with dominance of the $\mathrm{v}(\delta) 1$ subset in a healthy population. Int. Immunol. 12, 797-805. doi: $10.1093 /$ intimm/12.6.797

Hviid, L., Smith-Togobo, C., and Willcox, B. E. (2019). Human V $\delta 1(+)$ T cells in the immune response to plasmodium falciparum infection. Front. Immunol. 10:259. doi: 10.3389/fimmu.2019.00259

Imlach, S., Leen, C., Bell, J. E., and Simmonds, P. (2003). Phenotypic analysis of peripheral blood $\gamma \delta \mathrm{T}$ lymphocytes and their targeting by human immunodeficiency virus type 1 in vivo. Virology 305, 415-427. doi: $10.1006 /$ viro.2002.1759

James, K. S., Trumble, I., Clohosey, M. L., Moeser, M., Roan, N. R., Adimora, A. A., et al. (2020). Measuring the contribution of $\gamma \delta \mathrm{T}$ cells to the persistent HIV reservoir. Aids 34, 363-371. doi: 10.1097/QAD.0000000000002434

Juno, J. A., and Eriksson, E. M. (2019). $\gamma \delta$ T-cell responses during HIV infection and antiretroviral therapy. Clin. Transl. Immunol. 8:e01069. doi: $10.1002 /$ cti2.1069

Kohler, S. L., Pham, M. N., Folkvord, J. M., Arends, T., Miller, S. M., Miles, B., et al. (2016). Germinal center T follicular helper cells are highly permissive to HIV-1 and alter their phenotype during virus replication. J. Immunol. 196, 2711-2722. doi: 10.4049/jimmunol.1502174

Le Nours, J., Gherardin, N. A., Ramarathinam, S. H., Awad, W., Wiede, F., Gully, B. S., et al. (2019). A class of $\gamma \delta \mathrm{T}$ cell receptors recognize the underside of the antigen-presenting molecule MR1. Science 366, 1522-1527. doi: 10.1126/science.aav3900

Lee, W. S., Kristensen, A. B., Rasmussen, T. A., Tolstrup, M., Ostergaard, L., Sogaard, O. S., et al. (2017). Anti-HIV-1 ADCC antibodies following latency reversal and treatment interruption. J. Virol. 91:e00603-17. doi: 10.1128/JVI.00603-17

Li, Z., Jiao, Y., Hu, Y., Cui, L., Chen, D., Wu, H., et al. (2015). Distortion of memory $\mathrm{V} \delta 2 \gamma \delta \mathrm{T}$ cells contributes to immune dysfunction in chronic HIV infection. Cell Mol. Immunol. 12, 604-614. doi: 10.1038/cmi.2014.77

Li, Z., Li, W., Li, N., Jiao, Y., Chen, D., Cui, L., et al. (2014). $\gamma \delta$ T cells are involved in acute HIV infection and associated with AIDS progression. PLoS ONE 9:e106064. doi: 10.1371/journal.pone.0106064

Linette, G. P., Stadtmauer, E. A., Maus, M. V., Rapoport, A. P., Levine, B. L., Emery, L., et al. (2013). Cardiovascular toxicity and titin cross-reactivity of affinity-enhanced T cells in myeloma and melanoma. Blood 122, 863-871. doi: 10.1182/blood-2013-03-490565

Lo Presti, E., Pizzolato, G., Gulotta, E., Cocorullo, G., Gulotta, G., Dieli, F., et al. (2017). Current advances in $\gamma \delta \mathrm{T}$ cell-based tumor immunotherapy. Front. Immunol. 8:1401. doi: 10.3389/fimmu.2017.01401

Lundqvist, C., Baranov, V., Hammarstrom, S., Athlin, L., and Hammarstrom, M. L. (1995). Intra-epithelial lymphocytes. Evidence for regional specialization and extrathymic T cell maturation in the human gut epithelium. Int. Immunol. 7 , 1473-1487. doi: 10.1093/intimm/7.9.1473

Luteijn, R., Sciaranghella, G., Van Lunzen, J., Nolting, A., Dugast, A. S., Ghebremichael, M. S., et al. (2011). Early viral replication in lymph nodes provides HIV with a means by which to escape NK-cell-mediated control. Eur. J. Immunol. 41, 2729-2740. doi: 10.1002/eji.201040886

Madhavi, V., Ana-Sosa-Batiz, F. E., Jegaskanda, S., Center, R. J., Winnall, W. R., Parsons, M. S., et al. (2015). Antibody-dependent effector functions against HIV decline in subjects receiving antiretroviral therapy. J. Infect. Dis. 211, 529-538. doi: 10.1093/infdis/jiu486

Madhavi, V., Kulkarni, A., Shete, A., Lee, W. S., Mclean, M. R., Kristensen, A. B., et al. (2017). Effect of combination antiretroviral therapy on HIV-1specific antibody-dependent cellular cytotoxicity responses in subtype B- and subtype C-infected cohorts. J. Acquir. Immune Defic. Syndr. 75, 345-353. doi: 10.1097/QAI.0000000000001380

Malkovsky, M., Bartz, S. R., Mackenzie, D., Radtke, B. E., Wallace, M., Manning, J., et al. (1992). Are $\gamma \delta$ T cells important for the elimination of virus-infected cells? J. Med. Primatol. 21, 113-118.
Nakajima, H., Cella, M., Langen, H., Friedlein, A., and Colonna, M. (1999). Activating interactions in human NK cell recognition: the role of 2B4-CD48. Eur. J. Immunol. 29, 1676-1683. doi: 10.1002/(SICI)15214141(199905)29:05<1676::AID-IMMU1676>3.0.CO;2-Y

Nedellec, S., Sabourin, C., Bonneville, M., and Scotet, E. (2010). NKG2D costimulates human $\mathrm{V}$ gamma $9 \mathrm{~V}$ delta $2 \mathrm{~T}$ cell antitumor cytotoxicity through protein kinase $\mathrm{C}$ theta-dependent modulation of early TCRinduced calcium and transduction signals. J. Immunol. 185, 55-63. doi: 10.4049/jimmunol.1000373

Oliva, A., Kinter, A. L., Vaccarezza, M., Rubbert, A., Catanzaro, A., Moir, S., et al. (1998). Natural killer cells from human immunodeficiency virus (HIV)-infected individuals are an important source of CC-chemokines and suppress HIV-1 entry and replication in vitro. J. Clin. Invest. 102, 223-231. doi: 10.1172/JCI2323

Olson, G. S., Moore, S. W., Richter, J. M., Garber, J. J., Bowman, B. A., Rawlings, C. A., et al. (2018). Increased frequency of systemic pro-inflammatory $\mathrm{V} \delta 1(+) \gamma \delta$ T cells in HIV elite controllers correlates with gut viral load. Sci. Rep. 8:16471. doi: 10.1038/s41598-018-34576-4

Omi, K., Shimizu, M., Watanabe, E., Matsumura, J., Takaku, C., Shinya, E., et al. (2014). Inhibition of R5-tropic HIV type-1 replication in CD4(+) natural killer $\mathrm{T}$ cells by $\gamma \delta \mathrm{T}$ lymphocytes. Immunology 141, 596-608. doi: 10.1111/imm.12221

Pauza, C. D., and Cairo, C. (2015). Evolution and function of the TCR V $\gamma 9$ chain repertoire: it's good to be public. Cell Immunol. 296, 22-30. doi: 10.1016/j.cellimm.2015.02.010

Pauza, C. D., Liou, M. L., Lahusen, T., Xiao, L., Lapidus, R. G., Cairo, C., et al. (2018). $\Gamma \delta \mathrm{T}$ cell therapy for cancer: it is good to be local. Front Immunol 9 , 1305. doi: 10.3389/fimmu.2018.01305

Pitard, V., Roumanes, D., Lafarge, X., Couzi, L., Garrigue, I., Lafon, M. E., et al. (2008). Long-term expansion of effector/memory $\mathrm{V} \delta 2-\gamma \delta \mathrm{T}$ cells is a specific blood signature of CMV infection. Blood 112, 1317-1324. doi: 10.1182/blood-2008-01-136713

Pizzolato, G., Kaminski, H., Tosolini, M., Franchini, D. M., Pont, F., Martins, F., et al. (2019). Single-cell RNA sequencing unveils the shared and the distinct cytotoxic hallmarks of human TCRV $\delta 1$ and TCRV $\delta 2 \gamma \delta$ T lymphocytes. Proc. Natl. Acad. Sci. U.S.A. 116, 11906-11915. doi: 10.1073/pnas.18184 88116

Poccia, F., Battistini, L., Cipriani, B., Mancino, G., Martini, F., Gougeon, M. L., et al. (1999). Phosphoantigen-reactive V $\gamma 9 \mathrm{~V} \delta 2 \mathrm{~T}$ lymphocytes suppress in vitro human immunodeficiency virus type 1 replication by cell-released antiviral factors including CC chemokines. J. Infect. Dis. 180, 858-861. doi: $10.1086 / 314925$

Poccia, F., Boullier, S., Lecoeur, H., Cochet, M., Poquet, Y., Colizzi, V., et al. (1996). Peripheral $\mathrm{V} \gamma 9 / \mathrm{V} \delta 2 \mathrm{~T}$ cell deletion and anergy to nonpeptidic mycobacterial antigens in asymptomatic HIV-1-infected persons. J. Immunol. 157, 449-461.

Poccia, F., Cipriani, B., Vendetti, S., Colizzi, V., Poquet, Y., Battistini, L., et al. (1997). CD94/NKG2 inhibitory receptor complex modulates both anti-viral and anti-tumoral responses of polyclonal phosphoantigen-reactive $\mathrm{V}$ gamma 9V delta 2 T lymphocytes. J. Immunol. 159, 6009-6017.

Poccia, F., Gioia, C., Martini, F., Sacchi, A., Piacentini, P., Tempestilli, M., et al. (2009). Zoledronic acid and interleukin-2 treatment improves immunocompetence in HIV-infected persons by activating Vgamma9V $\delta 2 \mathrm{~T}$ cells. Aids 23, 555-565. doi: 10.1097/QAD.0b013e3283244619

Poggi, A., Carosio, R., Fenoglio, D., Brenci, S., Murdaca, G., Setti, M., et al. (2004). Migration of $\mathrm{V} \delta 1$ and $\mathrm{V} \delta 2 \mathrm{~T}$ cells in response to CXCR3 and CXCR4 ligands in healthy donors and HIV-1-infected patients: competition by HIV-1 Tat. Blood 103, 2205-2213. doi: 10.1182/blood-2003-08-2928elta

Poles, M. A., Barsoum, S., Yu, W., Yu, J., Sun, P., Daly, J., et al. (2003). Human immunodeficiency virus type 1 induces persistent changes in mucosal and blood $\gamma \delta \mathrm{T}$ cells despite suppressive therapy. J. Virol. 77, 10456-10467. doi: 10.1128/JVI.77.19.10456-10467.2003

Polito, V. A., Cristantielli, R., Weber, G., Del Bufalo, F., Belardinilli, T., Arnone, C. M., et al. (2019). Universal ready-to-use immunotherapeutic approach for the treatment of Cancer: expanded and activated polyclonal $\gamma \delta$ memory T cells. Front. Immunol. 10:2717. doi: 10.3389/fimmu.2019.02717

Poonia, B., and Pauza, C. D. (2012). $\Gamma \delta \mathrm{T}$ cells from HIV+ donors can be expanded in vitro by zoledronate/interleukin-2 to become cytotoxic 
effectors for antibody-dependent cellular cytotoxicity. Cytotherapy 14, 173-181. doi: 10.3109/14653249.2011.623693

Provine, N. M., Binder, B., Fitzpatrick, M. E. B., Schuch, A., Garner, L. C., Williamson, K. D., et al. (2018). Unique and common features of innatelike human $\mathrm{V} \delta 2(+) \gamma \delta \mathrm{T}$ cells and mucosal-associated invariant $\mathrm{T}$ cells. Front. Immunol. 9:756. doi: 10.3389/fimmu.2018.00756

Qaqish, A., Huang, D., Chen, C. Y., Zhang, Z., Wang, R., Li, S., et al. (2017). Adoptive transfer of phosphoantigen-specific $\gamma \delta \mathrm{T}$ cell subset attenuates mycobacterium tuberculosis infection in nonhuman primates. J Immunol. 198, 4753-4763. doi: 10.4049/jimmunol.1602019

Riedel, D. J., Sajadi, M. M., Armstrong, C. L., Cummings, J. S., Cairo, C., Redfield, R. R., et al. (2009). Natural viral suppressors of HIV-1 have a unique capacity to maintain $\gamma \delta$ T cells. Aids 23, 1955-1964. doi: 10.1097/QAD.0b013e32832ff1ff

Rincon-Orozco, B., Kunzmann, V., Wrobel, P., Kabelitz, D., Steinle, A., and Herrmann, T. (2005). Activation of V gamma 9V delta $2 \mathrm{~T}$ cells by NKG2D. J. Immunol. 175, 2144-2151. doi: 10.4049/jimmunol.175.4.2144

Rossol, R., Dobmeyer, J. M., Dobmeyer, T. S., Klein, S. A., Rossol, S., Wesch, D., et al. (1998). Increase in $\mathrm{V} \delta 1+\gamma \delta \mathrm{T}$ cells in the peripheral blood and bone marrow as a selective feature of HIV-1 but not other virus infections. $\mathrm{Br}$. J. Haematol. 100, 728-734. doi: 10.1046/j.1365-2141.1998.00630.x

Rotolo, R., Leuci, V., Donini, C., Cykowska, A., $\Gamma$ itoni, L., Medico, G., et al. (2019). CAR-based strategies beyond T Lymphocytes: integrative opportunities for cancer adoptive immunotherapy. Int. J. Mol. Sci. 20:2839. doi: 10.3390/ijms20112839

Roy, S., Ly, D., Castro, C. D., Li, N. S., Hawk, A. J., Altman, J. D., et al. (2016). Molecular analysis of lipid-reactive $\mathrm{V} \delta 1 \gamma \delta \mathrm{T}$ cells identified by CD1c tetramers. J. Immunol. 196, 1933-1942. doi: 10.4049/jimmunol.1502202

Shan, L., Deng, K., Shroff, N. S., Durand, C. M., Rabi, S. A., Yang, H. C., et al. (2012). Stimulation of HIV-1-specific cytolytic T lymphocytes facilitates elimination of latent viral reservoir after virus reactivation. Immunity 36, 491-501. doi: 10.1016/j.immuni.2012.01.014

Silva-Santos, B., Mensurado, S., and Coffelt, S. B. (2019). $\gamma \delta$ T cells: pleiotropic immune effectors with therapeutic potential in cancer. Nat. Rev. Cancer 19, 392-404. doi: 10.1038/s41568-019-0153-5

Simoes, A. E., di Lorenzo, B., and Silva-Santos, B. (2018). Molecular determinants of target cell recognition by human $\gamma \delta \mathrm{T}$ cells. Front. Immunol. 9:929. doi: 10.3389/fimmu.2018.00929

Sindhu, S. T., Ahmad, R., Morisset, R., Ahmad, A., and Menezes, J. (2003). Peripheral blood cytotoxic $\gamma \delta \mathrm{T}$ lymphocytes from patients with human immunodeficiency virus type 1 infection and AIDS lyse uninfected CD4+ $\mathrm{T}$ cells, and their cytocidal potential correlates with viral load. J. Virol. 77, 1848-1855. doi: 10.1128/JVI.77.3.1848-1855.2003

Smith, B. A., Gartner, S., Liu, Y., Perelson, A. S., Stilianakis, N. I., Keele, B. F., et al. (2001). Persistence of infectious HIV on follicular dendritic cells. J. Immunol. 166, 690-696. doi: 10.4049/jimmunol.166.1.690

Soriano-Sarabia, N., Archin, N. M., Bateson, R., Dahl, N. P., Crooks, A. M., Kuruc, J. D., et al. (2015). Peripheral V $\gamma 9 \mathrm{~V} \delta 2 \mathrm{~T}$ cells are a novel reservoir of latent HIV infection. PLoS Pathog. 11:e1005201. doi: 10.1371/journal.ppat.1005201

Strbo, N., Alcaide, M. L., Romero, L., Bolivar, H., Jones, D., Podack, E. R., et al. (2016). Loss of intra-epithelial endocervical gamma delta (GD) $1 \mathrm{~T}$ cells in HIVinfected women. Am. J. Reprod. Immunol. 75, 134-145. doi: 10.1111/aji.12458

Tanaka, Y., Morita, C. T., Tanaka, Y., Nieves, E., Brenner, M. B., and Bloom, B. R. (1995). Natural and synthetic non-peptide antigens recognized by human $\gamma \delta \mathrm{T}$ cells. Nature 375, 155-158. doi: 10.1038/375155a0

Triebel, F., Faure, F., Graziani, M., Jitsukawa, S., Lefranc, M. P., and Hercend, T. (1988). A unique V-J-C-rearranged gene encodes a $\gamma$ protein expressed on the majority of CD3+ T cell receptor-alpha/beta- circulating lymphocytes. J. Exp. Med. 167, 694-699. doi: 10.1084/jem.167.2.694

Tuero, I., Venzon, D., and Robert-Guroff, M. (2016). Mucosal and systemic $\gamma \delta+\mathrm{T}$ cells associated with control of simian immunodeficiency virus infection. J. Immunol. 197, 4686-4695. doi: 10.4049/jimmunol.16 00579
Tyler, C. J., Doherty, D. G., Moser, B., and Eberl, M. (2015). Human V $\gamma 9 / \mathrm{V} \delta 2 \mathrm{~T}$ cells: Innate adaptors of the immune system. Cell Immunol. 296, 10-21. doi: 10.1016/j.cellimm.2015.01.008

Uldrich, A. P., Le Nours, J., Pellicci, D. G., Gherardin, N. A., Mcpherson, K. G., Lim, R. T., et al. (2013). CD1d-lipid antigen recognition by the $\gamma \delta$ TCR. Nat. Immunol. 14, 1137-1145. doi: 10.1038/ni.2713

van Den Berg, J. H., Gomez-Eerland, R., van De Wiel, B., Hulshoff, L., Van Den Broek, D., Bins, A., et al. (2015). Case report of a fatal serious adverse event upon administration of $\mathrm{T}$ cells transduced With a MART-1-specific T-cell receptor. Mol. Ther. 23, 1541-1550. doi: 10.1038/mt.2015.60

van Der Heiden, M., Bjorkander, S., Rahman Qazi, K., Bittmann, J., Hell, L., Jenmalm, M. C., et al. (2020). Characterization of the $\gamma \delta$ T-cell compartment during infancy reveals clear differences between the early neonatal period and 2 years of age. Immunol. Cell Biol. 98, 79-87. doi: 10.1111/imcb.12303

Wallace, M., Bartz, S. R., Chang, W. L., Mackenzie, D. A., Pauza, C. D., and Malkovsky, M. (1996). $\Gamma \delta$ T lymphocyte responses to HIV. Clin. Exp. Immunol. 103, 177-184. doi: 10.1046/j.1365-2249.1996.d01-625.x

Wallace, M., Gan, Y. H., Pauza, C. D., and Malkovsky, M. (1994). Antiviral activity of primate gamma delta Tlymphocytes isolated by magnetic cell sorting. J. Med. Primatol. 23, 131-135. doi: 10.1111/j.1600-0684.1994.tb00113.x

Wallace, M., Scharko, A. M., Pauza, C. D., Fisch, P., Imaoka, K., Kawabata, S., et al. (1997). Functional $\gamma \delta$ T-lymphocyte defect associated with human immunodeficiency virus infections. Mol Med. 3, 60-71. doi: $10.1007 / \mathrm{BF} 03401668$

Ward, J., Bonaparte, M., Sacks, J., Guterman, J., Fogli, M., Mavilio, D., et al. (2007). HIV modulates the expression of ligands important in triggering natural killer cell cytotoxic responses on infected primary T-cell blasts. Blood 110, 1207-1214. doi: 10.1182/blood-2006-06-028175

Wesch, D., Hinz, T., and Kabelitz, D. (1998). Analysis of the TCR V $\gamma$ repertoire in healthy donors and HIV-1-infected individuals. Int. Immunol. 10, 1067-1075. doi: 10.1093/intimm/10.8.1067

Wilhelm, M., Smetak, M., Schaefer-Eckart, K., Kimmel, B., Birkmann, J., Einsele, H., et al. (2014). Successful adoptive transfer and in vivo expansion of haploidentical $\gamma \delta$ T cells. J. Transl. Med. 12:45. doi: 10.1186/1479-5876-12-45

Willcox, B. E., and Willcox, C. R. (2019). $\gamma \delta$ TCR ligands: the quest to solve a 500-million-year-old mystery. Nat. Immunol. 20, 121-128. doi: 10.1038/s41590-018-0304-y

Wong, J. K., and Yukl, S. A. (2016). Tissue reservoirs of HIV. Curr. Opin. HIV AIDS 11, 362-370. doi: 10.1097/COH.0000000000000293

Wrobel, P., Shojaei, H., Schittek, B., Gieseler, F., Wollenberg, B., Kalthoff, H., et al. (2007). Lysis of a broad range of epithelial tumour cells by human $\gamma \delta \mathrm{T}$ cells: involvement of NKG2D ligands and T-cell receptorversus NKG2D-dependent recognition. Scand. J. Immunol. 66, 320-328. doi: 10.1111/j.1365-3083.2007.01963.x

Wu, D., Wu, P., Wu, X., Ye, J., Wang, Z., Zhao, S., et al. (2015). Ex vivo expanded human circulating $\mathrm{V} \delta 1 \quad \gamma \delta \mathrm{T}$ cells exhibit favorable therapeutic potential for colon cancer. Oncoimmunology 4:e992749. doi: 10.4161/2162402X.2014.992749

Zhang, T., He, X., Tsang, T. C., and Harris, D. T. (2004). Transgenic TCR expression: comparison of single chain with full-length receptor constructs for T-cell function. Cancer Gene. Ther. 11, 487-496. doi: 10.1038/sj.cgt.7700703

Conflict of Interest: The authors declare that the research was conducted in the absence of any commercial or financial relationships that could be construed as a potential conflict of interest.

Copyright $\odot 2020$ Juno and Kent. This is an open-access article distributed under the terms of the Creative Commons Attribution License (CC BY). The use, distribution or reproduction in other forums is permitted, provided the original author(s) and the copyright owner(s) are credited and that the original publication in this journal is cited, in accordance with accepted academic practice. No use, distribution or reproduction is permitted which does not comply with these terms. 